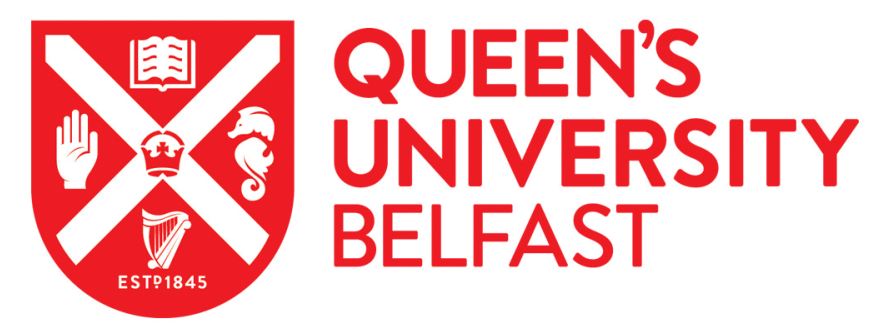

\title{
Core Outcome Sets: reaching consensus on what to measure in research
}

Millar, A., McGrattan, M., O'Sullivan, M., Rankin, A., \& Hughes, C. M. (2017). Core Outcome Sets: reaching consensus on what to measure in research. International Journal of Pharmacy Practice, 25(4), $251-252$. https://doi.org/10.1111/ijpp. 12378

\section{Published in:}

International Journal of Pharmacy Practice

\section{Document Version:}

Peer reviewed version

\section{Queen's University Belfast - Research Portal:}

Link to publication record in Queen's University Belfast Research Portal

\section{Publisher rights}

(c) 2017 Royal Pharmaceutical Society. This work is made available online in accordance with the publisher's policies. Please refer to any applicable terms of use of the publisher

\section{General rights}

Copyright for the publications made accessible via the Queen's University Belfast Research Portal is retained by the author(s) and / or other copyright owners and it is a condition of accessing these publications that users recognise and abide by the legal requirements associated with these rights.

Take down policy

The Research Portal is Queen's institutional repository that provides access to Queen's research output. Every effort has been made to ensure that content in the Research Portal does not infringe any person's rights, or applicable UK laws. If you discover content in the Research Portal that you believe breaches copyright or violates any law, please contact openaccess@qub.ac.uk. 


\section{Core Outcome Sets: reaching consensus on what to measure in research}

Anna Millar, Mairead McGrattan, Maureen O’Sullivan, Audrey Rankin and Carmel M. Hughes*

School of Pharmacy, Queen's University Belfast, 97 Lisburn Road, Belfast BT9 7BL

*Author for correspondence

In this so-called 'post-truth era', the importance of robust evidence has assumed more significance than ever. Healthcare needs to be informed by rigorous research that can underpin practice and healthcare delivery and ultimately improve outcomes for patients. But in the development and implementation of studies that will generate the necessary evidence, what outcomes should be measured? A cursory overview of studies performed in any given area reveals a huge number of outcomes being measured, making evidence synthesis and assessing the overall effectiveness of interventions very difficult. For example, Beuscart et al [1] undertook a systematic review of trials in medication review in older people, reporting that 327 different outcomes were identified in 47 published studies. There was marked heterogeneity in the outcomes used, with adverse events and patient-related outcomes poorly evaluated. In another field of research, more than 25,000 outcomes had appeared only once or twice in oncology trials [2]. Therefore, in an effort to overcome the issues of range and heterogeneity within outcome selection, the COMET (Core Outcome Measures in Effectiveness Trials) Initiative was established (http://comet-initiative.org/). COMET advocates for the development and application of agreed standardised sets of outcomes known as 'core outcome sets' (COSs). A COS represents the minimum that should be measured and reported in all trials of a specific condition or field of research [3]. The COMET website maintains a database of all ongoing and published COS studies to minimise duplication and share examples of good practice. Recently added COS projects include 'Development of an International Core Outcome Set for Best Care for the Dying Person', and 'Development of a provide core domain set for polymyalgia rheumatica' (http://comet-initiative.org/).

Guidance has been provided to help researchers develop a COS in any given area. The essential steps are: (1) establishing the scope of the COS, (2) identifying the existing knowledge, (3) stakeholder involvement and (4) a consensus exercise. Scope refers to the specific area of health or healthcare to which the COS will apply [3]. It should also consider the health condition, populations and types of interventions covered by the COS. For example, in the case of medicines use in older people, the scope may include all older people or only those who reside in care homes. Furthermore, the focus may include all medications, or only those used in the management of dementia. Identifying existing knowledge requires some form of literature search to establish what outcomes have been measured and reported in previous studies in the area. COS developers will often consult systematic reviews in 
the area of the COS or may undertake a systematic review to allow them to compile a list of outcomes for potential inclusion in a COS.

The third step in COS development is the involvement of key stakeholders. This may include patients and the public, healthcare professionals, regulators, industry representatives and researchers [3]. This list of stakeholders is not exhaustive, and their involvement should be informed by the scope of the COS in question. Stakeholder views, elicited through interviews or focus groups on what should be included in a COS, are essential to ensure that the outcomes selected are meaningful, not just from a clinical and scientific standpoint, but also from a patient's perspective. Identifying and accessing key patient and public stakeholders can be particularly challenging, but liaising with support groups, patient advocacy groups and/or charities may be a helpful strategy.

The fourth and final step in COS development is an exercise whereby stakeholder views are sought using a consensus method to condense the outcomes suggested in the preceding stages into the final COS. There is no single preferred consensus method, although the Delphi technique [4] has been widely used. This technique is a long-established method that facilitates informed decisionmaking by obtaining consensus from a range of opinions in areas of research where there is limited information. The Delphi technique can be applied through face-to-face stakeholder panel meetings led by a facilitator or via the completion of questionnaires distributed by post or online, or using a combination of a questionnaire followed by a face-to-face meeting. The list of outcomes compiled from existing knowledge and consultation with stakeholders, are presented to the Delphi panel members, who rate their importance, usually using some kind of numerical rating scale. One numerical scale has been proposed by the GRADE group [5] by which on a scale of 1-9, a rating of 13 indicates an outcome of 'limited importance', 4-6 'important but not critical' and 7-9 'critical'. Based on the ratings that are given, a decision will be made on whether, or not, there is consensus for including an outcome in a COS. Typically, consensus for inclusion in the COS is judged as having been achieved if $70 \%$ or more of responding stakeholders score an outcome 7-9 and fewer than $15 \%$ score it $1-3$. Outcomes for which no consensus is achieved are then presented to the panel to be rated again, alongside group and individual scores for each outcome from the first Delphi 'round'. In most studies, this process is repeated over three rounds, after which, outcomes not meeting the pre-defined threshold will not be included in the COS. Many COSs currently listed on the COMET website have broadly followed this approach to development, but the underpinning methodology is being refined in order to improve the rigour of the process. Indeed, in an attempt to improve the quality of published COSs, the Core Outcome Set-STAndards for Reporting (COS-STAR) guideline [6] 
has been developed, outlining the items that COS developers should report (e.g. data sources and stakeholder eligibility criteria).

There is growing interest in the use of appropriate COSs in pharmacy practice and medicines optimisation research. The COMET website lists several relevant COSs currently under development including: 'The development of a core outcome set (COS) for use in interventions aimed at improving appropriate polypharmacy in older people in primary care', 'A core outcome set for trials aimed at optimising prescribing in care homes' and 'Development of a core outcome set for medication review in older people'. These COSs clearly focus on the management of older people in situations where medicines use is highly prevalent, but where there is ongoing debate about how best to optimise use. It would be prudent for all pharmacy practice researchers to check the COMET website for any relevant COSs during the planning stages of their studies, in order to guide outcome selection.

It should be noted that a COS specifies what should be measured, as opposed to how it should be measured. The latter can be guided through the use of the COSMIN (Consensus-based Standards for the selection of health Measurement Instruments) checklist [7]. There is also a continuing debate as to how many outcomes should be included in a COS because it would not be desirable or feasible to measure multiple outcomes. There are still many challenges to the development of COSs that need to be addressed, but it is a rigorous and worthwhile process that should provide more definitive answers to what is both effective and important for patients and practitioners alike.

References

1. Beuscart JB et al. A systematic review of the outcomes reported in trials of medication review in older patients: the need for a core outcome set. Br J Clin Pharmacol 2016; doi: 10.1111/bcp.13197

2. Hirsch BR et al. Characteristics of oncology clinical trials: insights from a systematic analysis of ClinicalTrials.gov. JAMA Intern Med 2013; 173: 972-979.

3. Williamson PR et al. Developing core outcome sets for clinical trials: issues to consider. Trials 2012; 13: 132.

4. Campbell SM, Cantrill JA. Consensus methods in prescribing research. J Clin Pharm Ther 2008; 26: 5-14.

5. Guyatt GH et al. GRADE guidelines: 2. Framing the question and deciding on important outcomes. J Clin Epidemiol 2011; 64: 395-400.

6. Kirkham JJ et al. Core Outcome Set-STAndards for Reporting: The COS-STAR Statement. PLoS Med 2016; 13: e1002148. 
7. Mokkink LB et al. The COSMIN checklist for assessing the methodological quality of studies on measurement properties of health status measurement instruments: an international Delphi study. Qual Life Res 2010; 19: 539-549. 